May 2003 • NREL/CP-590-33570

\title{
Practical Doping Principles
}

\section{A. Zunger}

Presented at the National Center for Photovoltaics and Solar Program Review Meeting Denver, Colorado March 24-26, 2003

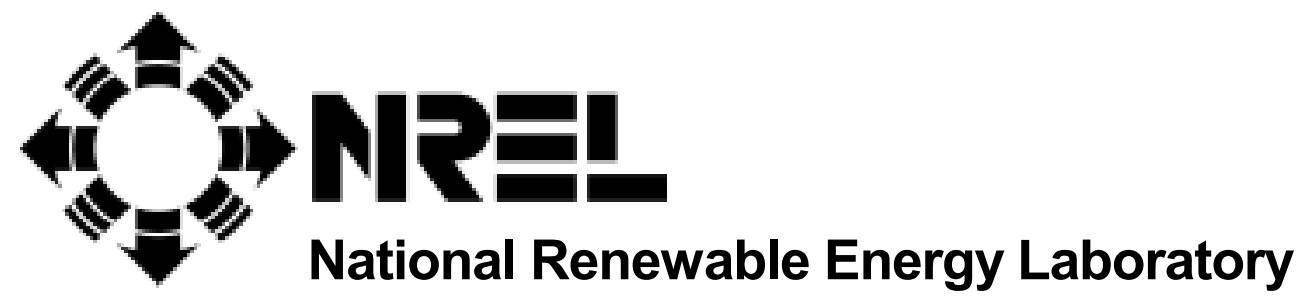

1617 Cole Boulevard Golden, Colorado 80401-3393

NREL is a U.S. Department of Energy Laboratory Operated by Midwest Research Institute • Battelle • Bechtel Contract No. DE-AC36-99-G010337 


\section{NOTICE}

The submitted manuscript has been offered by an employee of the Midwest Research Institute (MRI), a contractor of the US Government under Contract No. DE-AC36-99G010337. Accordingly, the US Government and MRI retain a nonexclusive royalty-free license to publish or reproduce the published form of this contribution, or allow others to do so, for US Government purposes.

This report was prepared as an account of work sponsored by an agency of the United States government. Neither the United States government nor any agency thereof, nor any of their employees, makes any warranty, express or implied, or assumes any legal liability or responsibility for the accuracy, completeness, or usefulness of any information, apparatus, product, or process disclosed, or represents that its use would not infringe privately owned rights. Reference herein to any specific commercial product, process, or service by trade name, trademark, manufacturer, or otherwise does not necessarily constitute or imply its endorsement, recommendation, or favoring by the United States government or any agency thereof. The views and opinions of authors expressed herein do not necessarily state or reflect those of the United States government or any agency thereof.

Available electronically at http://www.osti.gov/bridge

Available for a processing fee to U.S. Department of Energy and its contractors, in paper, from:

U.S. Department of Energy

Office of Scientific and Technical Information

P.O. Box 62

Oak Ridge, TN 37831-0062

phone: 865.576.8401

fax: 865.576.5728

email: reports@adonis.osti.gov

Available for sale to the public, in paper, from:

U.S. Department of Commerce

National Technical Information Service

5285 Port Royal Road

Springfield, VA 22161

phone: 800.553 .6847

fax: 703.605.6900

email: orders@ntis.fedworld.gov

online ordering: http://www.ntis.gov/ordering.htm

Printed on paper containing at least $50 \%$ wastepaper, including $20 \%$ postconsumer waste 


\title{
Practical Doping Principles
}

\author{
Alex Zunger \\ National Renewable Energy Laboratory, Golden, Colorado, 80401
}

\begin{abstract}
Theoretical investigations of doping of several wide-gap materials suggest a number of rather general, practical doping principles that may help guide experimental strategies of overcoming doping bottlenecks. This paper will be published as a journal article in the future.
\end{abstract}

Since the operation of carrier-transporting heterojunction devices is predicated on ambipolar ( $p$ and $-n$ type) doping, the failure to successfully dope certain classes of materials is an important bottleneck for the technological utilization of these materials in electronic devices. As the band gap of a material increases (e.g., $\mathrm{Si} \rightarrow \mathrm{GaAs} \rightarrow \mathrm{ZnSe} \rightarrow \mathrm{ZnO}$ ) it generally becomes increasingly difficult to dope it in a symmetric ( $\mathrm{n}$ and $\mathrm{p}$ type) fashion. For example, whereas diamond can be doped p-type, its n-type doping is rather difficult ${ }^{1}$; conversely, while $\mathrm{ZnO}^{2,3,4,5}$ and other main-group oxides ${ }^{6}$ can be readily doped $n$ type, their p-type doping is problematic. Striking doping irregularities also appear in compounds belonging to the same chemical class, e.g. AlN is difficult to dope n-type, whereas $\mathrm{GaN}$ can be readily doped n-type ${ }^{7} ; \mathrm{CuInSe}_{2}$ exhibits n-type conduction whereas $\mathrm{CuGaSe}_{2}$ exhibits only p-type ${ }^{8}$. Doping bottlenecks have attracted significant attention from both experimentalists (see reviews in Refs. 1,2) and theorists $^{4-17}$ who provided highly detailed studies on individual cases. Yet, this case-by-case focus has sometimes detracted from observing general regularities and formulating doping rules. In this work, I attempt to distill from recent theoretical studies of individual hard-to-dope systems ${ }^{4-17}$ some general, practical doping principles, loosely referred to as doping rules. Although such Pauling-esque rules do not cover all cases, or identify all exceptions, they might provide basic design guidelines for systematically navigating in the complex parameter space of experimental attempts to overcome doping bottlenecks. Detailed theoretical discussion is left out of this paper; the interested reader is referred to the original papers, e.g., Refs. 9-17.

I will divide the practical doping rules into those that emerge from (i) Fermi-level-induced compensation effects (spontaneous generation of killer defects ), (ii) the effects of adjusting the chemical potentials of the different elements, and (iii) local defect bonding effects. These three effects are encoded in the basic three-term formula that describes the formation enthalpy of dopant $D$ of charge state $\mathrm{q}$ in host crystal $\mathrm{H}$ :

$$
\Delta \mathrm{H}^{(D, q)}\left(\mu, \mathrm{E}_{F}\right)=q \mathrm{E}_{F}+n_{D}\left(\mu_{D}-\mu_{H}\right)+\Delta \mathrm{E}_{b},
$$

where $\mu_{\mathrm{D}}$ and $\mu_{\mathrm{H}}$ are the chemical potentials of the dopants and host, $E_{F}$ is the electro (chemical) potential (Fermi energy), $\mathrm{n}_{\mathrm{D}}$ is the number of dopants, $\Delta \mathrm{E}_{\mathrm{b}}=\mathrm{E}$ (host + defect)-E(host) is the excess energy of the local chemical bonds around the dopant and $\mathrm{E}$ is the total energy with respect to free-atoms. The doping rules discussed here pertain to ways of (i) avoiding Fermi-level-induced compensation effects by spontaneous generation of native killer defects, (ii) enhancing dopant solubility (i.e., lowering $\Delta \mathrm{H}^{(\mathrm{D}, \mathrm{q})}$ ) via control of chemical potentials. Enhanced solubility will (a) create sufficient dopants to overcome any counter compensating defects, and (b) broaden sufficiently the dopant energy level by impurity-impurity interaction so this band becomes close enough to the band edge, thus ionizable, (iii) stabilizing the bonding of the dopant to its local chemical environment so it does not diffuse away. These three effects correspond to the three terms in Eq. (1), respectively, as follows:

(i) Doping rules pertaining to Fermi-level-induced compensation effects: When an electron-producing donor $\alpha$ (charge $\mathrm{q}>0$ ) is incorporated into a solid, it donates electrons that join the free-carrier reservoir whose energy is $E_{F}$; thus, as Eq. (1) shows, the total donor formation energy increases linearly with $\mathrm{E}_{\mathrm{F}}$. Similarly, formation of electron-capturing acceptors (charge $\mathrm{q}<0$ ) entails removing $\mathrm{q}$ electrons from the Fermi reservoir, thus the acceptor formation energy decreases linearly with $\mathrm{E}_{\mathrm{F}}$. These trends are depicted schematically in Fig. 1a where the donor transition energy $\mathrm{E}(0 /+)$ is the value of the Fermi energy at which the formation enthalpy of the neutral defect $\alpha^{0}$ equals the formation energy of the positive defect $\alpha^{+}$. There is a parallel definition for the acceptor transition energy $\mathrm{E}(0 /-)$. It follows from the linear dependencies on $E_{F}$ that when we deliberately dope materials n-type (via donors), (thus shifting its $E_{F}$ towards the conduction band), the formation energy of native acceptors, such as cation vacancies $V_{C}^{-}$or DX centers will decrease to a point that such electron-killers will form spontaneously. 

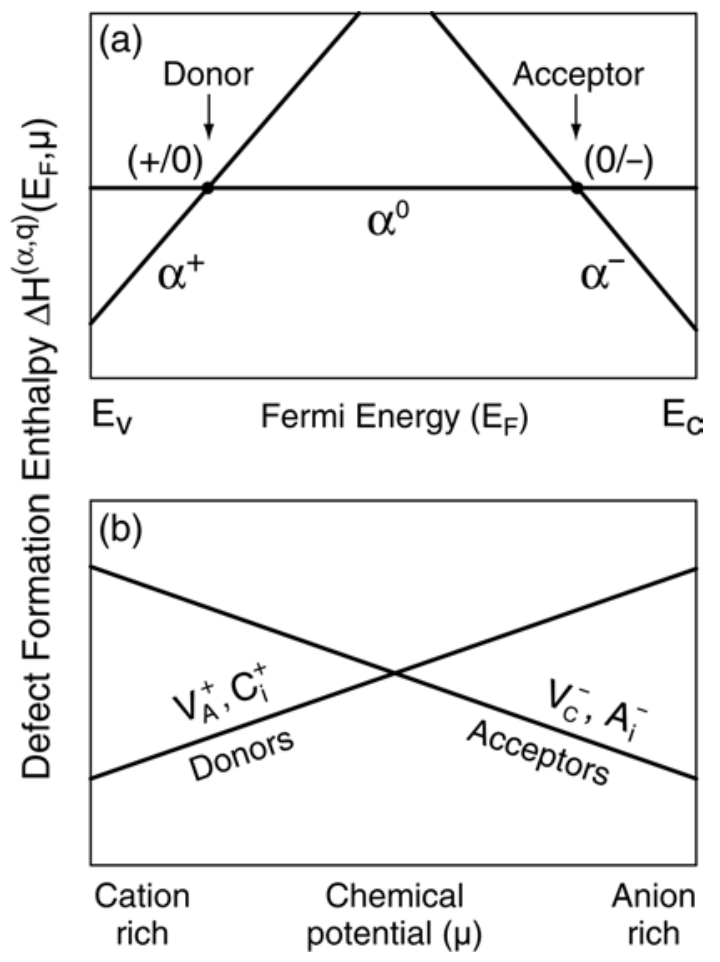

Fig. 1: (a) Schematic depiction of the dependence of the formation enthalpy of defect $\alpha$ in charge states $q$ $=+, 0$ and - on the Fermi energy. The solid dots denote the donor $(0 /+)$ and acceptor $(0 /-)$ transition energies. (b) Schematic depiction of the formation enthalpy of some intrinsic donors (anion vacancy $\mathrm{V}_{\mathrm{A}}$, cation interstitial $\mathrm{C}_{\mathrm{i}}$ ) and intrinsic acceptors (cation vacancy $V_{C}$ and anion interstitial $A_{i}$ ) on the chemical potential.

For example ${ }^{15}$, n-type doping of GaAs:Si is limited by the formation of $\mathrm{V}_{\mathrm{Ga}}$, whereas n-type doping of $\mathrm{Si}$ :As is limited ${ }^{16}$ by the formation of $\mathrm{V}_{\mathrm{Si}}$. At this value of $\mathrm{E}_{\mathrm{F}}$, called n-type pinning energy $\mathrm{E}_{F}^{(n)}$, no further progress in $\mathrm{n}$-doping can be made, since the spontaneously generated electron killers will negate the deliberately introduced donors. Similarly, deliberate $\mathrm{p}$-doping by acceptors (shifting $\mathrm{E}_{\mathrm{F}}$ towards the valence band) will instigate at some point $\mathrm{E}_{F}^{(p)}$ called p-type pinning energy the spontaneous formation of native hole killers such as anion vacancy $V_{A}^{+}$or cation interstitial $C_{i}^{+}$at which point ptype doping stops. Figure 2 shows the approximate positions of $\mathrm{E}_{F}^{(n)}$ and $\mathrm{E}_{F}^{(p)}$ in a number of group III-V and II-VI semiconductors, as obtained from firstprinciples calculations ${ }^{10}$ and independently from measured carrier densities ${ }^{9,11}$.

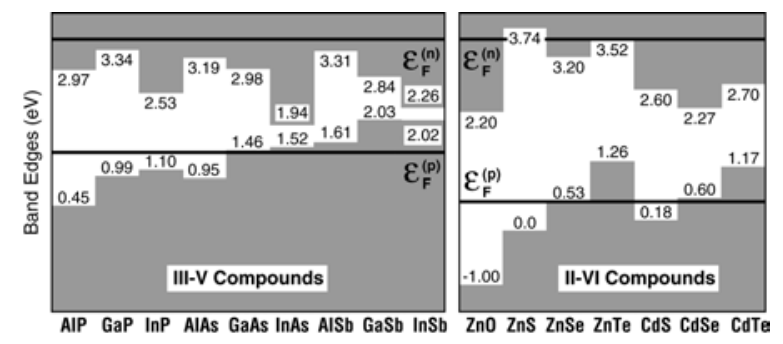

Fig. 2: The n-type pinning energy $\varepsilon_{F}^{(n)}$ and p-type pinning energy $E_{F}^{(p)}$ are shown relative to the absolute band-edge energies (from Ref. 18) of III-V and II-VI semiconductors.

In this figure the valence band maxima were aligned according to the calculated (unstrained) band offsets, collected in Ref. 18 for most compound semiconductors, whereas the band gap values are taken from low-temperature experimental data. There is an approximate alignment of the pinning levels (horizontal lines) within given chemical groups of compounds. The positions of the pining levels with respect to the host crystal band edges determine dopability. For example, in $\mathrm{ZnO}$ or $\mathrm{ZnS}$ the $\mathrm{E}_{F}^{(p)}$ level is considerably above the VBM. Thus, the downwards-moving $\mathrm{E}_{\mathrm{F}}$ in deliberate p-type doping will encounter $E_{F}^{(p)}$ before encountering the VBM. At this point the system will generate spontaneous hole-killers (e.g., $\mathrm{Zn}_{\mathrm{i}}$ or $\mathrm{V}_{\mathrm{O}}$ ) before any significant doping commences. In contrast, in Tellurides or Antimonides $\mathrm{E}_{F}^{(p)}$ is at or below the VBM, so a considerable amount of holes can be generated before the pinning energy is encountered and killer defects form. Corresponding rules refer to electron-doping and its pinning by spontaneous formation of electron killers (Fig. 3 summarizes all doping rules). The relevant doping rules are:

Rule 1: $\quad$-type doping is facilitated by materials whose conduction band minima (CBM) are far from the vacuum level, i.e., materials with large bulkintrinsic electron affinities $\chi$. Conversely, n-type doping tends to be compensated in materials with small bulk-intrinsic electron affinities. This rule reflects the difficulty in n-type doping of AlN (Ref. 7) or diamond ${ }^{1}(\chi \cong 0)$, the ease of n-type doping InAs and $\mathrm{ZnO}$ (very large $\chi$ ). This rule further suggests that lowering the CBM via selective alloying (e.g., adding nitrogen to III-V s which leads to huge downwards CBM bowing) will enhance n-type doping. ${ }^{19}$ Any creative chemical modification that lowers the CBM may also facilitate n-type doping. 
Rule 2: $\quad$-type doping is facilitated by materials whose valence band maximum (VBM) is close to the vacuum level, i.e., small bulk-intrinsic ionization potential $\Phi$. Conversely, p-type doping tends to be compensated in materials with large bulk-intrinsic ionization energies. This rule reflects the ease of $\mathrm{p}$ type doping of antimonides and tellurides (small $\Phi$ ), and the difficulty in p-type doping of the more electronegative oxides and sulphides (large $\Phi)$. The rule suggests that enhanced p-type doping can be facilitated by alloying an element that leads to upward-bowing of the VBM, e.g., an active delectron metal that repels upwards the VBM (viz. the p-typeness of $\mathrm{CuAlO}_{2}$ (Ref. 20) relative to oxides such as $\mathrm{MgO}$ or $\mathrm{ZnO}$ that lack shallow d-states). Any creative chemical modification that raises the VBM may also facilitate $\mathrm{p}$-type doping.

Rules 1 and 2 explain why diamond is difficult to dope n-type ${ }^{1}(\chi$ only $<0.2 \mathrm{eV}$ ) but it is easier to dope diamond p-type ( $\Phi$ as low as $\sim 5 \mathrm{eV}$ ), whereas the other form of carbon ${ }^{21} \mathrm{C}_{60}$ is easy to dope n-type $(\chi$ as big as $2.7 \mathrm{eV}$ ), but difficult to dope p-type ( $\Phi$ as big as $7.6 \mathrm{eV}$ ). Also, Rules 1 and 2, taken together imply that ambipolar doping requires, in general, a small minimum (not optical) gap (large $\chi$ and small $\Phi$, where $\mathrm{Eg}=\Phi-\chi)$, a well-known result. But these rules clarify that the origin of doping asymmetry in different materials depends on $\chi$ and $\Phi$ separately.

The next rules refer to ways of eliminating the particular pinning centers ( kill the killer ).

\section{Rule 3: $\quad$ Since n-type doping is inhibited by}

electron-killers such as the cation vacancy $V_{C}^{-}$, this can be overcome by designing growth conditions which destabilize cation vacancies (kill the killer), e.g., the use of cation-rich growth conditions. Naturally, the extent of attainable cation-richness is limited by the requirement of not precipitating competing cation phases such as elemental cation metals or cation-dopant compounds.

Rule 4: $\quad$ Since p-type doping is inhibited by holekillers such as anion vacancy $V_{A}^{+}$and cation interstitials $C_{i}^{+}$, this can be overcome by designing growth conditions which destabilize these defects (kill the killer), e.g., the use of anion-rich growth conditions, or agents that form complexes with cation interstitials. Naturally, the extent of attainable anion-richness is limited by the requirement of not precipitating competing anion phases such as elemental anion metal or anion-dopant complexes. This rule suggests, for example, that p-type doping of oxides can be facilitated by creating internal oxygen precipitates that eliminate oxygen vacancies, e.g., using $\mathrm{NO}$ or $\mathrm{NO}_{2}$ sources ${ }^{3,5}$ for nitrogen-doping of
$\mathrm{ZnO}$, or $\mathrm{Li}_{2} \mathrm{O}$ sources for Li-doping of $\mathrm{MgO}$ (Ref. 22).

(ii) Doping rules pertaining to chemical potential effects: It is well known ${ }^{23}$ that the solubility of two solids A and B can be enhanced via epitaxy-induced solubility. That is, if $\mathrm{A}$ and $\mathrm{B}$ are bulk-immiscible solids because of a significant size-mismatch, growing them coherently on a substrate that is mismatched with $\mathrm{A}$ and $\mathrm{B}$, but more closely matched with their alloy $\mathrm{A}_{1-\mathrm{x}} \mathrm{B}_{\mathrm{x}}$ will lower the $\mathrm{A}+\mathrm{B} \rightarrow \mathrm{A}_{1-\mathrm{x}} \mathrm{B}_{\mathrm{x}}$ mixing-enthalpy, thus enhance solubility. This effect results $^{23}$ from a strain-destabilization of A-onsubstrate + B-on-substrate, not from stabilizing the $A_{1-x} B$ alloy itself. Examples include ${ }^{23}$ the epitaxial solubility of $\mathrm{GaP}+\mathrm{InP}$ or $\mathrm{GaAs}+\mathrm{GaN}$ on a $\mathrm{GaAs}$ substrate. The same principle of lowering $\Delta \mathrm{H}$ by destabilizing the reactants can be applied to epitaxially enhance dopant solubility, e.g., growth of the host crystal on a strained substrate can enhance dopant solubility. ${ }^{17}$ The competing phase (e.g., dopant-host compound) will be destabilized, thus enhancing dopant solubility. A similar idea - that of obtaining the required solubility by destabilization of the reactants - can also be used to enhance dopability, namely impinging on the growing surface high-energy, relatively chemically unstable dopant sources $^{3,5}$ (e.g., $\mathrm{NO}, \mathrm{NO}_{2}$ for $\mathrm{N}$-doping) rather than low-energy stable sources (e.g., $\mathrm{N}_{2}$ ) to lower the enthalpy of doping.

In general, the second term of Eq. (1) shows how $\Delta \mathrm{H}$ for formation of anionic or cationic dopants can be regulated via control of the chemical potentials during growth (Fig. 1b). This figure illustrates the fact that the enthalpy of forming anion vacancies decreases under cation-rich conditions, whereas the enthalpy of forming cation vacancies decreases under anion-rich conditions.

Rule 5: Anion-substituting dopants will be more soluble under host anion poor (=host cation rich) growth conditions. This rule reflects the fact that defects that donate host anions to the chemical reservoir (e.g., anion vacancy $V_{A}^{+}$or cation antisite $C_{A}^{+}$) are easier to form if this reservoir has low anion chemical potential $\mu_{\mathrm{A}}$ (i.e., anion-poor). Thus, p-type $\mathrm{Zn} \underline{\mathrm{O}}: \mathrm{N}$ or n-type $\mathrm{ZnO}$ :F are best grown under $\mathrm{Zn}$-rich conditions $^{24}$ and p-type $\mathrm{GaAs}$ : $\mathrm{C}$ is best grown under Ga-rich conditions. n-type doping via anion substitutions (using anion-poor conditions) satisfies simultaneously rules 3 and 5, e.g., n-type Znㅁ: F.

Rule 6: Cation-substituting dopants will be more soluble under host-cation poor (=host anion rich) growth conditions. This rule reflects the fact that defects which donate host cations to the chemical reservoir (e.g., $V_{C}^{-}$or anion interstitial $A_{i}^{-}$) are easier 
to form if this reservoir has low cation chemical energy $\mu_{\mathrm{C}}$ (cation poor). Indeed, p-type GaAs:Zn or GaAs:Mn are best grown under As-rich conditions (low-temperature growth). P-type doping via cation substitution (using cation-poor conditions) satisfies simultaneously rules 4 and 6, e.g., p-type GaAs:Zn.

If one desires to attempt n-type doping via cation substitution, by Rule 6 one needs cation-poor conditions. However, by Rule 3 this could enhance the formation of electron killer $\mathrm{V}_{\mathrm{C}}$. One then needs to defeat the spontaneous formation of cation vacancy electron-killers. Similarly, if one desires to attempt p-type doping via anion substitution, by Rule 5 one needs anion-poor conditions. However, by Rule 4 this could enhance the formation of hole killer $V_{A}$. Then, one needs somehow to defeat the spontaneous formation of anion vacancy hole-killers. Thus, it may prove easier to do p-type doping via cation-site substitution using anion-rich conditions, whereas ntype doping can be done via anion-site substitution using cation-rich conditions. These points are illustrated in Fig. 3.

\begin{tabular}{|c|c|c|}
\hline & n-Type Doping & p-Type Doping \\
\hline Killer defects & $\mathrm{V}_{\mathrm{C}}^{-}, \mathrm{A}_{\mathrm{i}}^{+}[1]$ & $\mathrm{V}_{\mathrm{A}}^{+}, \mathrm{C}_{\mathrm{i}}^{+}[2]$ \\
\hline $\begin{array}{l}\text { To avoid killer, } \\
\text { use }\end{array}$ & $\begin{array}{l}\text { - Low CBM [1] } \\
\text { - Cation rich [3] }\end{array}$ & $\begin{array}{l}\text { - High VBM [2] } \\
\text { - Anion rich [4] }\end{array}$ \\
\hline $\begin{array}{l}\text { To enhance } \\
\text { solubility on } \\
\text { anion site, } \\
\text { use }\end{array}$ & Anion poor [5] & Anion poor [5] \\
\hline $\begin{array}{l}\text { To enhance } \\
\text { solubility on } \\
\text { cation site, } \\
\text { use }\end{array}$ & Cation poor [6] & Cation poor [6] \\
\hline
\end{tabular}

Fig. 3: Summary of the doping rules.

(iii) Doping rules pertaining to local defect bonding effects: Even if one enhances the dopant solubility via epitaxy, use of highly-reactive source materials, or doping rules 5 and 6 , there is no guarantee that the dopant will remain stable on its desired lattice site, for its local chemical bonds might be weak. For example, although large concentration of $\mathrm{N}$ can now be introduced into ${ }^{3} \mathrm{ZnO}$, the desired p-type doping is often unstable over time, since the nitrogen bond to $\mathrm{Zn}$ is not as stable as the original $\mathrm{Zn}-\mathrm{O}$ bond $\left(\Delta \mathrm{E}_{\mathrm{b}}>0\right.$ in Eq. 1). This limitation might be overcome via cluster doping ${ }^{14}$ :

Rule 7: $\quad$ The local chemical bonding energy around the dopant could be enhanced via decorating the dopant by strongly-bonding ligands which do not disrupt the host bonds. For example, whereas the four $\mathrm{Zn}-\mathrm{N}$ bonds formed when $\mathrm{N}$ dopes the $\mathrm{O}$ site in $\mathrm{ZnO}$ are weak, addition of $\mathrm{Al}$ in a Al-to-N ratio of $4: 1$ creates four very strong $\mathrm{Al}-\mathrm{N}$ bonds around $\mathrm{Al}_{\mathrm{Zn}}$, followed by twelve weak $\mathrm{Zn}-\mathrm{N}$ bonds around each of the four $\mathrm{N}$ sites. Since AlN is extremely stable, $\Delta \mathrm{E}_{\mathrm{b}}=4 \mathrm{E}_{\mathrm{Al}-\mathrm{N}}+12 \mathrm{E}_{\mathrm{Zn}-\mathrm{N}}<0$. Such cluster doping ideas could facilitate stable local dopant bonding and enhanced solubility. Many chemical combinations can be explored, e.g., p-type doping of II-VI crystal by replacing the VI-atom and its four II-atom neighbors by the cluster of $\mathrm{V}-\mathrm{III}_{4}$. Interestingly, this cluster-doping is predicted to be stabler than codoping. ${ }^{25}$

The seven practical doping rules described here could provide guidelines for creative, educated experimentations with various doping strategies for difficult-to-dope wide-gap materials.

This work was supported by the U.S. D.O.E. through EERE, Contract DEAC36-98-GO10337.

\section{REFERENCES}

[1.] R. Kalish, Diamond and Related Mater. 10, 1749 (2001).

[2.] G.F. Neumark, Mat. Sci. and Engineering R21, 46 (1997).

[3.] M. Joseph, H. Tabuta, T. Kawai, Japan J. Appl. Phys. 38, L1205 (1999).

[4.] S.B. Zhang, S.-H. Wei and A. Zunger, Phys. Rev. B. 39, 8776 (1989).

[5.] Y. Yan, S.B. Zhang and S. Pantelides, Phys. Rev. Lett. 86, 5723 (2001).

[6.] C. Kilic and A. Zunger, Phys. Rev. Lett. 88, 095501 (2002).

[7.] J. Hwang et al., Appl. Phys. Lett. (In Press); M.D. Bremser et al., J. Elec. Mat. 27, 229 (1998).

[8.] S.B. Zhang, S.H. Wei, A. Zunger and H. KatayamaYoshida, Phys. Rev. B 57, 9642 (1998).

[9.] S.B. Zhang, S.H. Wei and A. Zunger, J. Appl. Phys. 83, 3192 (1998).

[10.] S.B. Zhang, S.H. Wei and A. Zunger, Phy. Rev. Lett. 84, 1232 (2000).

[11.] W. Walukiewitz, Phys. Rev. B 39, 8776 (1989).

[12.] C. Van de Walle, Phys. Rev. Lett. 85, 1012 (2000).

[13.] C. Kilic and A. Zunger, Appl. Phys. Lett. 80, 73 (2002).

[14.] L. Wang and A. Zunger (unpublished).

[15.] J.E. Northrup and S.B. Zhang, Phys. Rev. B 47, 6791 (1993).

[16.] M. Ramamoorthy and S.T. Pantelides, Phys. Rev. Lett. 76, 4753 (1996).

[17.] L. Wang and A. Zunger, Phys. Rev. B 66, 161202 (2002). 
[18.] S.H. Wei and A. Zunger, Appl. Phys. Lett. 72, 2011 (1998).

[19.] K. Uesugi and I Suemune, Appl. Phys. Lett. 79, 3284 (2001).

[20.] H. Kawazoe et al., Nature 389, 939 (1997). H. Kawazoe and K. Ueda, J. Am. Ceram. Soc. 82, 3330 (1999).

[21.] C.J. Brabec et al., Adv. Funct. Mater. 11, 374 (2001).

[22.] Y. Chen et al., Solid State Commun. 33, 441 (1980). J. de Physique C6 41, 398 (1980).

[23.] A. Zunger in Handbook of Crystal Growth edited by D.T.J. Hurle, Elsevier, Amsterdam, Vol. 3, p. 998 (1994).

[24.] D.M. Wood and A. Zunger, Phys. Rev. Lett. 61, 1501 (1988).

[25.] K. Nakahara et al., J. Crystal Growth 237-239, 503 (2002).

[26.] H. Katayama-Yoshida et al., J. Phys. Condensed Matter 13, 8901 (2001). 
Public reporting burden for this collection of information is estimated to average 1 hour per response, including the time for reviewing instructions, searching existing data sources,

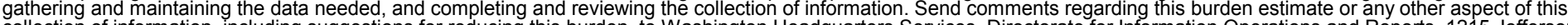

Davis Highway, Suite 1204, Arlington, VA 22202-4302, and to the Office of Management and Budget, Paperwork Reduction Project (0704-0188), Washington, DC 20503.
1. AGENCY USE ONLY (Leave blank)
2. REPORT DATE
May 2003
3. REPORT TYPE AND DATES COVERED
Conference Paper

4. TITLE AND SUBTITLE

Practical Doping Principles

5. FUNDING NUMBERS

PVP3.2101

6. AUTHOR(S)

A. Zunger

7. PERFORMING ORGANIZATION NAME(S) AND ADDRESS(ES)

National Renewable Energy Laboratory

1617 Cole Blvd.

Golden, CO 80401-3393

9. SPONSORING/MONITORING AGENCY NAME(S) AND ADDRESS(ES)

8. PERFORMING ORGANIZATION REPORT NUMBER

NREL/CP-590-33570

10. SPONSORING/MONITORING AGENCY REPORT NUMBER

11. SUPPLEMENTARY NOTES

12a. DISTRIBUTION/AVAILABILITY STATEMENT

National Technical Information Service

12b. DISTRIBUTION CODE

U.S. Department of Commerce

5285 Port Royal Road

Springfield, VA 22161

13. ABSTRACT (Maximum 200 words)

'Theoretical investigations of doping of several wide-gap materials suggest a number of rather general, practical "doping principles" that may help guide experimental strategies of overcoming doping bottlenecks. This paper will be published as a journal article in the future.

14. SUBJECT TERMS doping; wide-gap materials; theory; practical principles

15. NUMBER OF PAGES

16. PRICE CODE

17. SECURITY CLASSIFICATION OF REPORT Unclassified

18. SECURITY CLASSIFICATION OF THIS PAGE Unclassified
19. SECURITY CLASSIFICATION OF ABSTRACT Unclassified
20. LIMITATION OF ABSTRACT

UL 